\title{
Sobrevivência e desenvolvimento de lagartas de Spodoptera frugiperda e Chrysodeixis includens alimentadas com folhas de algodoeiro geneticamente modificado
}

\author{
Elmo Ponte de Melo ${ }^{1}$ \\ Raphael Maia Aveiro Cessa ${ }^{2}$ \\ Paulo Eduardo Degrande ${ }^{3}$ \\ Danilo Renato Santiago Santana ${ }^{4}$
}

\section{Resumo}

A cultura do algodão (Gossypium hirsutum L.) é hospedeira de um complexo de pragas que pode ocasionar danos às raízes, caule, folhas, botões florais, flores, maçãs, sementes e fibras. Este trabalho objetivou avaliar, por meio da alimentação com folhas de algodoeiro geneticamente modificadas resistentes a lepidópteros, a sobrevivência e o desenvolvimento de lagartas de Spodoptera frugiperda e Chrysodeixis includens. Os experimentos foram conduzidos no Laboratório de Entomologia Aplicada da Universidade Federal da Grande Dourados, Dourados, Mato Grosso do Sul, no período de 05 de janeiro (preparo dos vasos) a 23 de junho de 2012 (algodoeiros em fim de ciclo, com 154 dias após a emergência). As plantas foram cultivadas em casa de vegetação, enquanto os biotestes de sobrevivência e desenvolvimento de lagartas foram conduzidos em laboratório. Os estudos foram constituídos de: $\mathbf{A}$ - oferta de folhas de algodoeiro Coker TwinLink ${ }^{\circledR}$ e Cooker não modificada a lagartas de S. frugiperda; B - oferta de folhas de algodoeiro Coker TwinLink ${ }^{\circledR}$ e Cooker não modificada a lagartas de C. includens; C - oferta de folhas de algodoeiro PHY 440 WS Widestrike ${ }^{\circledR}$, FM 975 WS Widestrike ${ }^{\circledR}$ e FM 933 não modificado a lagartas de S. frugiperda; D - oferta de folhas de algodoeiro PHY 440 WS Widestrike ${ }^{\circledR}$, FM 975 WS Widestrike ${ }^{\circledR}$ e FM 933 não modificado a lagartas de C. includens. Compilando as informações do presente estudo, observamos que o algodoeiro Coker TwinLink ${ }^{\circledR}$ permitiu menores valores percentuais de sobrevivência de lagartas neonatas de $C$. includens se comparada à S. frugiperda. As linhagens de algodoeiros resistentes a lepidópteros interferem de forma negativa na sobrevivência e desenvolvimento de lagartas de S. frugiperda e $C$. includens, quando comparadas às linhagens não modificadas. Dependendo da linhagem, do evento geneticamente modificado e da praga, é necessário controle complementar.

Palavras-chave: Programa de melhoramento. Resistência de plantas. Proteínas.

\footnotetext{
1 Centro Universitário da Grande Dourados, professor da Faculdade de Agronomia. Dourados, Mato Grosso do Sul, Brasil. elmoah@hotmail.com. Rua Balbina de Matos, 2121, Jardim Universitário, Dourados, MS, CEP 79824-900.

2 Instituto Federal de Educação, Ciência e Tecnologia do Mato Grosso - Campus Confresa, professor do Ensino Básico, Técnico e Tecnológico - Área Agronomia. Confresa, Mato Grosso, Brasil. raphael.cessa@cfs.ifmt.edu.br. Avenida Vilma Fernandes, 300, Setor Santa Luzia, Confresa, MT, CEP 78652-000.

3 Universidade Federal da Grande Dourados, professor da Faculdade de Ciências Agrárias. Dourados, Mato Grosso do Sul, Brasil. pragas@uol.com.br. Rodovia Dourados - Itahum, Km 12, Aeroporto, Dourados, MS, CEP 78804-970.

4 Universidade Federal da Grande Dourados, acadêmico de Pós-graduação em Agronomia. Dourados, Mato Grosso do Sul, Brasil. danilosantana1987@hotmail.com. Rodovia Dourados - Itahum, Km 12, Aeroporto, Dourados, MS, CEP 78804-970.
} 


\section{Introdução}

A cultura do algodão (Gossypium hirsutum L.) é hospedeira de um complexo de pragas que pode ocasionar danos às raízes, caule, folhas, botões florais, flores, maçãs, sementes e fibras (GALLO et al., 2002; SANTOS, 2011). Os níveis populacionais dessas pragas variam, e infestações elevadas provocam sérios prejuízos à cultura. Sendo assim, as táticas de controle (cultural, químico, comportamental, genético, biotecnológico e biológico) do Manejo Integrado de Pragas (MIP) quando bem aplicadas são importantes nas boas práticas agrícolas e no sucesso do controle. O uso do MIP tem aumentado devido à grande demanda de conservação ambiental e economicidade da cotonicultura, além de contribuir para a manutenção e sustentação de antigas e novas tecnologias de controle de pragas à disposição dos produtores (GALLO et al., 2002).

Encontram-se liberadas para comercialização e cultivo sementes de algodoeiros transgênicos que expressam proteínas oriundas da bactéria Bacillus thuringiensis (BERLINER), 1911 (Bt), que causam a morte de muitos insetos, principalmente lepidópteros (BERNARDI; OMOTO, 2012; FONTES et al., 2002). O algodoeiro-Bt é cultivado em diversos países, com benefícios diretos, como a redução de custos de manejo de pragas, e indiretos, advindos da redução do uso de inseticidas (TORRES; RUBERSON; WHITEHOUSE, 2009). A expressão das proteínas de resistência de plantas, inseridas por meio da biotecnologia, varia em função das partes do vegetal e do estádio de desenvolvimento da cultura (SANTOS; TORRES, 2009). As tecnologias atualmente liberadas para serem utilizadas no cultivo no Brasil controlam pragas da Ordem Lepidoptera, mas existem diferenças entre as tecnologias no que diz respeito às espécies de insetos que são controladas (BERNARDI; OMOTO, 2012).

Entre as pragas do algodoeiro, a lagarta-militar Spodoptera frugiperda (Lepidoptera: Noctuidae) e lagarta-falsa-medideira Chrysodeixis includens (Lepidoptera: Noctuidae) têm sido citadas como sendo de relativa importância (MIRANDA; FERREIRA, 2005). S. frugiperda usualmente alimenta-se de folhas, botões florais e maçãs, enquanto $C$. includens alimenta-se de folhas, sendo consideradas relativamente tolerantes à proteína Cry 1 Ac, de $B$. thuringiensis, expressada nos genomas do algodoeiro com a tecnologia Bollgard ${ }^{\circledR}$, por exemplo, no controle de outras lagartas.

Este trabalho objetivou avaliar a sobrevivência e desenvolvimento de lagartas de S. frugiperda e $C$. includens alimentadas com folhas de algodoeiro geneticamente modificados resistentes a lepidópteros.

\section{Material e métodos}

Os experimentos foram conduzidos no Laboratório de Entomologia Aplicada da Universidade Federal da Grande Dourados, Dourados, Mato Grosso do Sul, no período de 05 de janeiro (preparo dos vasos) a 23 de junho de 2012 (algodoeiros em fim de ciclo, com 154 dias após a emergência). As plantas foram cultivadas em casa de vegetação, enquanto os biotestes de sobrevivência e desenvolvimento de lagartas foram conduzidos em laboratório.

Os algodoeiros foram cultivados em vasos preenchidos com $10 \mathrm{~kg}$ de Latossolo Vermelho Distroférrico, coletado na profundidade de $0-30 \mathrm{~cm}$, cujos resultados das análises química e física, de acordo com a EMBRAPA (1997) foram os seguintes, em mmol $\mathrm{dm}^{-3}: 1,6(\mathrm{~K}), 11,9(\mathrm{Al}), 17,9$ (Ca), 7,7 (Mg), 89 (H+Al), 27,2 (SB) e 116,2 (T); em mg dm³: 22,8 (M.O.) e 1 (P); pH em H $\mathrm{O}_{2}$ : 5,1; pH em $\mathrm{CaCl}_{2}: 4,0$; em g kg-1: $(245,30) \mathrm{SiO}_{2},(0,32) \mathrm{P}_{2} \mathrm{O}_{5},(10,21) \mathrm{TiO}_{2},(255,40) \mathrm{Fe}_{2} \mathrm{O}_{5},(272,16)$ $\mathrm{Al}_{2} \mathrm{O}_{5}, 760$ (argila), 90,9 (silte), 89,2 (areia grossa), 60,2 (areia fina); em g cm${ }^{-3}:$ 1,22 (densidade do solo) e 2,08 (densidade de partículas); em $\mathrm{cm}^{3} \mathrm{dm}^{-3}: 416$ (volume total de poros). 
A correção da acidez do solo deu-se pelo método da saturação de bases, considerando um valor de $\mathrm{V} \%$ de 70, com uso de calcário dolomítico, sendo o período de incubação do corretivo de 21 dias. Posteriormente, incorporou-se a adubação dos macro e micronutrientes ao solo nos vasos, consoante Novais, Neves e Barros (1991), realizando-se em seguida a semeadura. Aos $12^{\circ}$ e $23^{\circ}$ dias após a semeadura, efetuaram-se as adubações de cobertura por meio de soluções nutritivas quantificadas igualmente para cada vaso, com os seguintes nutrientes e respectivas dosagens em $\mathrm{mg} \mathrm{dm}^{-3}$ : N (25), $\mathrm{K}$ (25). 0 teor de umidade nos vasos foi mantido ocupando-se com água $60 \%$ do volume total de poros, calculado a partir dos valores de densidade do solo e de partículas (EMPRESA BRASILEIRA DE PESQUISA AGROPECUÁRIA - EMBRAPA, 1997).

A semeadura dos algodoeiros nos vasos deu-se no dia 18 de janeiro de 2012, posicionando as sementes de algodoeiro a um centímetro de profundidade e quatro delas por vaso. Sete dias após a emergência das plântulas, procedeu-se ao desbaste, deixando duas plantas por vaso, de tamanho e aparências visuais uniformes.

Foram conduzidos em laboratório estudos com oferta de folhas de linhagens de algodoeiro resistentes a lepidópteros para lagartas neonatas (primeiro ínstar) das espécies S. frugiperda e C. includens.

As linhagens de algodoeiros resistentes a lepidópteros testados foram Coker TwinLink ${ }^{\circledR}$, criado a partir do cruzamento entre as variedades de algodão Coker 315 e Coker 312, PHY 440 WS e FM 975 WS, contendo a tecnologia Widestrike ${ }^{\circledR}$, criada pela introdução do gene cry1F, originalmente isolado da bactéria de solo Bacillus thuringiensis, FM 993 não modificado e Coker não modificada.

Os estudos foram constituídos de A: oferta de folhas de algodoeiro Coker TwinLink ${ }^{\circledR}$ e Cooker não modificada a lagartas de S. frugiperda; B: oferta de folhas de algodoeiro Coker TwinLink ${ }^{\circledR}$ e Cooker não modificada a lagartas de C. includens; C: oferta de folhas de algodoeiro PHY 440 WS Widestrike ${ }^{\circledR}$, FM 975 WS Widestrike ${ }^{\circledR}$ e FM 933 não modificado a lagartas de S. frugiperda; D: oferta de folhas de algodoeiro PHY 440 WS Widestrike ${ }^{\circledR}$, FM 975 WS Widestrike ${ }^{\circledR}$ e FM 933 não modificado a lagartas de $C$. includens.

Para cada cultivar de algodoeiro havia oito vasos, com duas plantas cada um, constituindo em uma repetição para cada vaso. Nos estudos A e B havia, portanto, dois tratamentos e oito repetições e nos estudos $C$ e $D$ havia três tratamentos e oito repetições. $O$ delineamento experimental dos quatro estudos foi inteiramente casualizado.

No momento da infestação das lagartas em placas de Petri, folhas dos algodoeiros foram coletadas, lavadas com solução de hipoclorito de sódio a 1 \% e enxaguadas com água destilada. Em seguida, foram postas para secar em bancadas do laboratório sobre folhas de papel. As folhas foram coletadas nas seguintes idades das plantas nos vasos (dias após a emergência = DAE): 28, 42, 56, 70, 84, 98, 112, 126, 140 e 154 DAE.

Em cada placa de Petri foi disposta uma folha de algodoeiro proveniente do quinto nó a partir do ápice do caule, no qual se fez a infestação com 10 lagartas neonatas da espécie por placa, identificando-se a parcela e a data da infestação. As lagartas neonatas de S. frugiperda e C. includens foram oriundas de laboratórios de criação massal que forneciam ovos das espécies. A infestação era feita em até 24 horas após a eclosão. Nesse período de espera de até 24 horas, as lagartas eram mantidas em dieta artificial. Todas avaliações foram realizadas cinco dias após as infestações, quando foram observados os indivíduos mortos e vivos para o posterior cálculo da mortalidade. As lagartas sobreviventes, após esperados cinco dias de consumo, foram medidas quanto ao tamanho (em $\mathrm{mm}$ ) para posterior categorização de escala descrita na tabela 1. 
Tabela 1. Categorização dos escores para indivíduos (lagartas de S. frugiperda e C. includens ) sobreviventes após cinco dias das realizações dos testes de sobrevivência associados aos seus comprimentos

\begin{tabular}{lll}
\hline Condição & $\begin{array}{l}\text { Tamanho } \\
(\mathrm{mm})\end{array}$ & Escore \\
\hline Indivíduo morto & - & 0 \\
Sobrevivente L1 & $<5$ & 1 \\
Sobrevivente L2 & $5-8$ & 2 \\
Sobrevivente L3 & $8-12$ & 3 \\
Sobrevivente L4 & $>12$ & 4 \\
\hline
\end{tabular}

Fonte: Elaboração dos autores

As placas de Petri com as folhas e lagartas foram mantidas nas seguintes condições: temperatura de $25 \pm 2{ }^{\circ} \mathrm{C}$, umidade relativa de $75 \% \pm 10 \%$ e fotofase de 14 horas.

\section{Resultados e discussão}

Nos estudos A e B, pode-se observar que folhas do algodoeiro Coker TwinLink ${ }^{\circledR}$ ofertadas às lagartas de $S$. frugiperda e $C$. includens proporcionaram taxas de sobrevivências com variações entre 30 e $50 \%$ e no máximo $10 \%$ respectivamente no decorrer dos diferentes estágios fenológicos do algodoeiro. 0 algodoeiro Coker não modificado proporcionou sobrevivência superior a 85 e 70 \% respectivamente entre as espécies de lagartas. Lagartas alimentadas com folhas do algodoeiro Coker TwinLink ${ }^{\circledR}$ e sobreviventes cinco dias após a oferta das suas folhas tiveram escores menores que aquelas observadas no evento Coker não modificado, possivelmente ocasionado por efeitos deletérios da transgenia (Tabelas 2, 3, 4 e 5).

Tabela 2. Sobrevivência de lagartas de S. frugiperda em cinco épocas de avaliação após oferta de folhas de algodoeiro Coker TwinLink ${ }^{\circledR}$ e Coker não modificada

\begin{tabular}{lllllllllll}
\hline & 28 DAE & & 42 DAE & & 56 DAE & & 70 DAE & & 84 DAE \\
\cline { 2 - 10 } & Vivas (\%) & E & Vivas (\%) & E & Vivas (\%) & E & Vivas (\%) & E & Vivas (\%) & E \\
\hline TwinLink & 50 & 3 & 30 & 3 & 45 & 3 & 40 & 3 & 50 & 3 \\
Coker & 95 & 4 & 100 & 4 & 95 & 4 & 95 & 4 & 100 & 4 \\
\hline
\end{tabular}

DAE: dias após emergência do algodoeiro nos vasos; E: escore

Fonte: Elaboração dos autores

Tabela 3. Sobrevivência de lagartas de S. frugiperda em cinco épocas de avaliação após oferta de folhas de algodoeiro Coker TwinLink ${ }^{\circledR}$ e Coker não modificada

\begin{tabular}{lllllllllll}
\hline & 98 DAE & & 112 DAE & & 126 DAE & & 140 DAE & & 154 DAE & \\
\cline { 2 - 10 } & Vivas (\%) & E & Vivas (\%) & E & Vivas (\%) & E & Vivas (\%) & E & Vivas (\%) & E \\
\cline { 2 - 10 } TwinLink & 0 & 0 & 35 & 3 & 40 & 3 & 50 & 3 & 45 & 3 \\
Coker & 0 & 0 & 85 & 4 & 100 & 4 & 100 & 4 & 95 & 4 \\
\hline
\end{tabular}

DAE: dias após emergência do algodoeiro nos vasos; E: escore

Fonte: Elaboração dos autores 
Tabela 4. Sobrevivência de lagartas de $C$. includens em cinco épocas de avaliação após oferta de folhas de algodoeiro Coker TwinLink ${ }^{\circledR}$ e Coker não modificada

\begin{tabular}{lllllllllll}
\hline & 28 DAE & & 42 DAE & & 56 DAE & & 70 DAE & & 84 DAE \\
\cline { 2 - 9 } & Vivas (\%) & E & Vivas (\%) & E & Vivas (\%) & E & Vivas (\%) & E & Vivas (\%) & E \\
\cline { 2 - 9 } TwinLink & 10 & 2 & 10 & 2 & 0 & 0 & 0 & 0 & 10 & 2 \\
Coker & 85 & 4 & 70 & 4 & 75 & 4 & 85 & 4 & 95 & 4 \\
\hline
\end{tabular}

DAE: dias após emergência do algodoeiro nos vasos; E: escore

Fonte: Elaboração dos autores

Tabela 5. Sobrevivência de lagartas de $C$. includens em cinco épocas de avaliação após oferta de folhas de algodoeiro Coker TwinLink ${ }^{\circledR}$ e Coker não modificada

\begin{tabular}{lllllllllll}
\hline & 98 DAE & & 112 DAE & & 126 DAE & & 140 DAE & \multicolumn{2}{c}{ 154 DAE } & \\
\cline { 2 - 9 } TwinLink & Vivas (\%) & E & Vivas (\%) & E & Vivas (\%) & E & Vivas (\%) & E & Vivas (\%) & E \\
\cline { 2 - 9 } Coker & 0 & 0 & 0 & 0 & 10 & 2 & 0 & 0 & 5 & 2 \\
\hline
\end{tabular}

DAE: dias após emergência do algodoeiro nos vasos; E: escore

Fonte: Elaboração dos autores

Nos estudos C e D, observou-se que a transgenia Widestrike ${ }^{\circledR}$ contida nas folhas dos algodoeiros FM 975 WS ofertadas às lagartas de $S$. frugiperda e $C$. includens promoveu mortalidade total de indivíduos, exceto aos 42 DAE com 10 \% de sobrevivência para S. frugiperda (Tabelas 6, 7, 8 e 9). Para o algodoeiro PHY 440 WS Widestrike ${ }^{\circledR}$, observou-se sobrevivência entre 2 e $5 \%$ e 5 e $10 \%$ ao longo dos períodos de avaliação para S. frugiperda e C. includens, respectivamente. No algodoeiro FM 993 não modificado, a sobrevivência das lagartas de $S$. frugiperda e C. includens foi superior a 80 \%, exceto aos 56 DAE, com 60 \% de sobrevivência de lagartas de S. frugiperda e aos 42 DAE, com $70 \%$ de sobrevivência de lagartas de $C$. includens.

Tabela 6. Sobrevivência de lagartas de S. frugiperda em cinco épocas de avaliação após oferta de folhas de algodoeiro contendo os eventos PHY 440 WS Widestrike ${ }^{\circledR}$, FM 975 WS Widestrike ${ }^{\circledR}$ e FM 993

\begin{tabular}{llllllllllll}
\hline & 28 DAE & & 42 DAE & & 56 DAE & & 70 DAE & \multicolumn{2}{c}{ 84 DAE } & \\
\cline { 2 - 10 } PHY440 WS & Vivas (\%) & E & Vivas (\%) & E & Vivas (\%) & E & Vivas (\%) & E & Vivas (\%) & E \\
\cline { 2 - 10 } FM 993 & 3 & 2 & 2 & 2 & 2 & 1 & 5 & 2 & 5 & 2 \\
FM 975 WS & 80 & 4 & 85 & 4 & 60 & 4 & 90 & 4 & 100 & 4 \\
\hline
\end{tabular}

DAE: dias após emergência do algodoeiro nos vasos; E: escore

Fonte: Elaboração dos autores

Tabela 7. Sobrevivência de lagartas de S. frugiperda em cinco épocas de avaliação após oferta de folhas de algodoeiro contendo os eventos PHY 440 WS Widestrike ${ }^{\circledR}$, FM 975 WS Widestrike ${ }^{\circledR}$ e FM 993

\begin{tabular}{lllllllllll}
\hline & 98 DAE & & 112 DAE & & 126 DAE & & 140 DAE & & 154 DAE & \\
\cline { 2 - 10 } & Vivas (\%) & E & Vivas (\%) & E & Vivas (\%) & E & Vivas (\%) & E & Vivas (\%) & E \\
\cline { 2 - 10 } PHY440 WS & 0 & 0 & 5 & 2 & 5 & 2 & 5 & 2 & 3 & 2 \\
FM 993 & 0 & 0 & 85 & 4 & 100 & 4 & 100 & 4 & 95 & 4 \\
FM 975 WS & 0 & 0 & 0 & 0 & 0 & 0 & 0 & 0 & 0 & 0 \\
\hline
\end{tabular}

DAE: dias após emergência do algodoeiro nos vasos; E: escore

Fonte: Elaboração dos autores 
Tabela 8. Sobrevivência de lagartas de $C$. includens em cinco épocas de avaliação após oferta de folhas de algodoeiro contendo os eventos PHY 440 WS, FM 993 e FM 975 WS

\begin{tabular}{lllllllllll}
\hline & 28 DAE & & 42 DAE & & 56 DAE & & 70 DAE & \multicolumn{2}{c}{ 84 DAE } & \\
\cline { 2 - 10 } & Vivas (\%) & E & Vivas (\%) & E & Vivas (\%) & E & Vivas (\%) & E & Vivas (\%) & E \\
\hline PHY440 WS & 0 & 0 & 5 & 1 & 0 & 0 & 0 & 0 & 10 & 1 \\
FM 993 & 80 & 4 & 70 & 4 & 85 & 4 & 85 & 4 & 95 & 4 \\
FM 975 WS & 0 & 0 & 0 & 0 & 0 & 0 & 0 & 0 & 0 & 0 \\
\hline
\end{tabular}

DAE: dias após emergência do algodoeiro nos vasos; E: escore

Fonte: Elaboração dos autores

Tabela 9. Sobrevivência de lagartas de $C$. includens em cinco épocas de avaliação após oferta de folhas de algodoeiro contendo os eventos PHY 440 WS Widestrike ${ }^{\circledR}$, FM 975 WS Widestrike ${ }^{\circledR}$ e FM 993

\begin{tabular}{lllllllllll}
\hline & 98 DAE & & 112 DAE & & 126 DAE & & 140 DAE & & 154 DAE \\
\cline { 2 - 10 } & Vivas (\%) & E & Vivas (\%) & E & Vivas (\%) & E & Vivas (\%) & E & Vivas (\%) & E \\
\hline PHY440 WS & 0 & 0 & 0 & 0 & 5 & 1 & 0 & 0 & 5 & 1 \\
FM 993 & 0 & 0 & 85 & 4 & 95 & 4 & 100 & 4 & 90 & 4 \\
FM 975 WS & 0 & 0 & 0 & 0 & 0 & 0 & 0 & 0 & 0 & 0 \\
\hline
\end{tabular}

DAE: dias após emergência do algodoeiro nos vasos; E: escore

Fonte: Elaboração dos autores

Lagartas de S. frugiperda alimentadas com folhas do algodoeiro FM 975 WS Widestrike ${ }^{\circledR}$ e sobreviventes aos 42 DAE tiveram escore 1 para lagartas de $S$. frugiperda. Os escores observados para o algodoeiro PHY 440 WS Widestrike ${ }^{\circledR}$ foram, em geral, inferiores àqueles observados para 0 evento FM 993 não modificado.

Aos 98 DAE, todas as lagartas de S. frugiperda e C. includens morreram após a oferta de folhas de algodoeiro em todos os estudos. A esse fato, atribuiu-se uma pulverização com inseticida Acefato 750 PS (1.000 g do produto comercial diluídos em 400 L de água) para controle da população de mosca branca Bemisia tabaci efetuada aos 95 DAE.

Nos quatro ensaios realizados no presente trabalho, como observado por Soberón, Gill e Bravo (2009), a transgenia foi expressa continuamente nos tecidos da planta, o que explica a eficácia dessa tecnologia no controle de lagartas-pragas. Mendes et al. (2008), avaliando a incidência e os danos da S. frugiperda sob infestação artificial, verificaram diferença significativa de danos entre as versões de milho transgênico (plantas sem dano) e não transgênico (plantas com muitas folhas e cartucho totalmente destruído).

Ainda, no presente trabalho, houve semelhança com os resultados observados por Moraes, Lourenção e Paterniani (2015), em que danos ocasionados por lagartas de S. frugiperda foram mais severos nos híbridos convencionais de milho do que em suas "versões transgênicas", considerando que toxinas transgênicas diferentes promovem diferenças entre os graus de dano avaliado para a referida lagarta. Mendes e Waquil (2009) afirmam que é possível haver respostas diferenciadas em relação ao controle da lagarta-do-cartucho com a utilização de eventos transgênicos diferentes, complementando que em um mesmo grupo de insetos a atividade de cada toxina é diferenciada, pois toxinas Cry $1 \mathrm{~A}(\mathrm{~b})$ e Cry $1 \mathrm{~F}$ têm elevada especificidade sobre lepidópteros praga do milho, mas estudos toxicológicos constataram diferenças significativas em nível de toxicidade para cada espécie.

Waquil, Vilella e Foster (2002) observaram diferentes níveis de resistência dos híbridos de milho a $S$. frugiperda e os que expressavam as toxinas Cry $1 \mathrm{~F}$, Cry $1 \mathrm{~A}(\mathrm{~b})$, Cry $1 \mathrm{~A}(\mathrm{c})$ e Cry $9 \mathrm{C}$ foram 
considerados altamente resistente, resistente, moderadamente resistente e suscetível, respectivamente. Portanto, os melhores resultados obtidos sobre a sobrevivência de lagartas neonatas de $S$. frugiperda e C. includens com os algodoeiros FM 975 WS Widestrike ${ }^{\circledR}$ e PHY 440 WS Widestrike ${ }^{\circledR}$ em comparação ao algodoeiro Coker TwinLink ${ }^{\circledR}$ foi devido aos seus genes que expressam as proteínas tóxicas aos insetos. Os algodoeiros FM 975 WS Widestrike ${ }^{\circledR}$ e PHY 440 WS Widestrike ${ }^{\circledR}$ contêm o gene cry $1 F$ (expressa a proteína Cry $1 \mathrm{~F}$ equivalente àquela original de Bacillus thuringiensis). O Coker TwinLink ${ }^{\circledR}$ contém os genes cry $1 A b$ e cry2Ae, que expressam proteínas equivalentes às proteínas originais de Bacillus thuringiensis, além do gene e bar (obtido do genoma da bactéria Streptomyces hygroscopicus e expressa a proteína fosfinotricina-N-acetil-transferase, responsável pela inativação do efeito herbicida do glufosinato de amônio).

É importante ressaltar que a expressão de toxinas a insetos pelos genes transgênicos inseridos em plantas pode variar em graus de eficiência em condições de campo, níveis diferentes de infestação da praga, estádio fenológico da cultura, época do ano e localização geográfica do cultivo (FERNANDES et al., 2003). Outro fato é que há menor mortalidade de lagartas em últimos ínstares (DUTTON; ROMEIS; BIGLER, 2005), pois nos primeiros ínstares as lagartas são mais sensíveis às toxinas em razão das alterações na atividade específica de preoteases no suco intestinal. Keller et al. (1996) demonstraram que o suco intestinal dos últimos ínstares de S. littoralis tem alta atividade proteolítica, capaz de degradar completamente a proteína Cry 1C.

Compilando as informações do presente estudo, observamos que o algodoeiro Coker TwinLink $^{\circledR}$ permitiu menores valores percentuais de sobrevivência de lagartas neonatas de C. includens do que para S. frugiperda. Os algodoeiros FM 975 WS Widestrike ${ }^{\circledR}$ e PHY 440 WS Widestrike ${ }^{\circledR}$ permitiram menores valores de sobrevivência para lagartas neonatas de $C$. includens do que para S. frugiperda. Já o algodoeiro FM 975 WS Widestrike ${ }^{\circledR}$ proporcionou menor sobrevivência percentual de lagartas neonatas de S. frugiperda e $C$. includens se comparado com os algodoeiros PHY 440 WS Widestrike ${ }^{\circledR}$ e Coker TwinLink ${ }^{\circledR}$. Portanto, dependendo da linhagem, do evento geneticamente modificado e da praga, pode ser necessário controle complementar. Essa estratégia pode ser, inclusive, útil para o manejo da resistência, pois o controle dos sobreviventes no algodoeiro geneticamente modificado certamente contribuirá para a redução da seleção de raças resistentes (MENDES; WAQUIL 2009).

Os resultados observados no presente estudo vêm ao encontro dos resultados observados por diversos autores que relatam que as plantas transgênicas ou plantas geneticamente modificadas que expressam genes com atividade inseticida é mais uma ferramenta importante para o controle de insetos e para melhoria dos resultados das lavouras, além de serem consoantes à filosofia do manejo integrado de pragas (BEDIN et al., 2015; LIMA JÚNIOR et al., 2013; MAIA, 2005).

Uma abordagem aplicada, evidente no presente estudo, ao Manejo Integrado de Pragas (MIP) seria que as plantas transgênicas não substituem as táticas já existentes de controle; entretanto, elas são uma nova abordagem ao MIP, por poder eliminar ou reduzir drasticamente o uso de inseticidas não seletivos, favorecendo a aliança com o controle biológico e por reduzir o risco de resistência de insetos aos produtos químicos. Sendo assim, a possibilidade da utilização conjunta do controle biológico e da resistência de plantas por meio das plantas geneticamente modificadas tem assumido importância nas últimas décadas, pois, além do potencial de maior eficiência do controle biológico nas variedades resistentes, os inimigos naturais podem retardar o processo de adaptação da praga às plantas transgênicas (FRIZZAS; OLIVEIRA, 2006). 


\title{
Conclusões
}

As linhagens de algodoeiros resistentes a lepidópteros interferem de forma negativa na sobrevivência e desenvolvimento de lagartas de $S$. frugiperda e $C$. includens, quando comparadas às linhagens não modificadas. Dependendo da linhagem, do evento geneticamente modificado e da praga, é necessário controle complementar.

\section{Survival and development of Spodoptera frugiperda and Chrysodeixis includens larvae fed with genetically modified cotton plants}

\begin{abstract}
The crop cotton (Gossypium hirsutum L.) is host for a complex of pests that can cause damage to the roots, stem, leaves, flower buds, flowers, ball, seeds and fibers. This study aimed to evaluate the survival and development of caterpillars of Spodoptera frugiperda and Chrysodeixis includens fed with insect-resistant transgenic cotton leaves. The experiments were conducted at the Laboratório de Entomologia Aplicada da Universidade Federal da Grande Dourados, Dourados, Mato Grosso do Sul, in the period of January 5 (vase arrangements) to June 2012 (cotton at the end of the cycle, 154 days after the emergency). The plants were grown in a greenhouse, while bioassays survival and development of caterpillars were conducted in the laboratory. The studies consisted of: A - supply of cotton leaves Coker TwinLink ${ }^{\circledR}$ and unmodified Cooker at S. frugiperda caterpillars; B - supply of cotton leaves Coker TwinLink ${ }^{\circledR}$ and unmodified Cooker the crawler $C$. includens; C - supply of cotton leaves PHY 440 WS WideStrike, FM 975 and FM 933 WS unmodified WideStrike the larvae of S. frugiperda; D - supply of cotton leaves PHY 440 WS WideStrike, FM 975 and FM 933 WS unmodified WideStrike the crawler C. includens. Compiling the information from this study, we observed that the cotton Coker TwinLink ${ }^{\circledR}$ allowed smaller percentages of survival of neonate larvae of $C$. includens compared to S. frugiperda. When compared to the unmodified strains, the cotton strains resistant to lepidopteran interfere negatively on the survival and development of caterpillars of S. frugiperda and C. includens. Depending on the strain, the genetically modified event and pest, complement control is required.
\end{abstract}

Keywords: Breeding program. Plant resistance. Proteins.

\section{Referências}

BEDIN, F. A.; ASSMANN, E. J.; POLO, L. R. T.; SCHUSTER, I. Eficiência de eventos transgênicos de resistência a insetos em soja e milho. Revista Cultivando o Saber, v. 8, n. 2, p. 201-214, 2015.

BERNARDI, O.; OMOTO, C. Tecnologia preservada. Cultivar Grandes Culturas, v. 14, n. 155, p. 1013, 2012.

DUTTON, A.; ROMEIS, J.; BIGLER, F. Effects of Bt maize expressing Cry1Ab and Bt spray on Spodoptera littoralis. Entomologia Experimentalis Applicata, v. 114, n. 3, p. 161-169, 2005.

EMPRESA BRASILEIRA DE PESQUISA AGROPECUÁRIA - EMBRAPA. Manual de método de análise de solo. Rio de Janeiro, 2. ed. 1997. 212p. 
FERNANDES, O. D.; PARRA, J. R. P.; FERREIRA NETO, A.; PÍCOLI, R.; BORGATO, A. F.; DEMÉTRIO, C. G. B. Efeito do milho geneticamente modificado MON810 sobre a lagarta-do-cartucho Spodoptera frugiperda (J. E. Smith 1797) (Lepidoptera: Noctuidae). Revista Brasileira de Milho e Sorgo, v. 2, n. 2 , p. 25-35, 2003.

FONTES, E. M. G.; PIRES, C. S. S.; SUJII, E. R.; PANIZZI, A. R. The environmental effects of genetically modified crops resistant to insects. Neotropical Entomology, v. 31, n. 4. p. 497-513, 2002.

FRIZZAS, M. R.; OLIVEIRA, C. M. Plantas transgênicas resistentes a insetos e organismos não-alvo: predadores, parasitóides e polinizadores. Universitas: Ciências da Saúde, v. 4, n. 1/2, p. 63-82, 2006.

GALLO, D.; NAKANO, O.; SILVEIRA NETO, S.; CARVALHO, R. P. L.; BATISTA, G. C.; BERTI FILHO, E; PARRA, J. R. P.; ZUCCHI, R. A.; ALVES, S. B.; VENDRAMIN, J. D.; MARCHINI, L. C.; LOPES J. R. S.; OMOTO, C. Entomologia Agrícola. 3 ed. Piracicaba-SP: Agronômica Ceres. FEALQ, 2002.

KELLER, M.; SNEH, B.; STRIZHOV, N.; PRUDOVSKY, E.; REGEV, A.; KONCZ, C.; SCHELL, J.; ZILBERSTEIN, A. Digestion of delta-endotoxin by gut proteases may explain reduced sensitivity of advanced instar larvae of Spodoptera littoralis to Cry1C. Insect Biochemistry and Molecular Biology, v. 25, n. 3, p. 365-373, 1996.

LIMA JÚNIOR, I. S. de; DEGRANDE, P. E.; BERTONCELlO, T. F.; MELO, E. P. de; SUEKANE, R. Avaliação quantitativa do impacto do algodão-bt na população de araneae, carabidae e formicidae predadores ocorrentes sobre o solo. Bioscience Journal, v. 29, n. 1, p. 32-40, 2013.

MAIA, A. H. N. Definindo estratégias de manejo da resistência de pragas a toxinas Bt expressas em culturas transgênicas: o papel dos modelos de simulação. Embrapa Meio Ambiente, Jaguariúna, 2005.

MENDES, S. M., MARUCCI, R. C., MOREIRA, S. G., WAQUIL, J. M. Milho Bt: avaliação preliminar da resistência de híbridos comerciais à lagarta do cartucho, Spodoptera frugiperda (J. E. Smith, 1797). Sete Lagoas: Embrapa Milho e Sorgo, 2008. Comunicado técnico, 157.

MENDES, S. M.; WAQUIL, J. M. Uso do milho Bt no manejo integrado de lepidópteros praga: recomendações de uso Sete Lagoas: Embrapa Milho e Sorgo, 2009. 8 p. (Embrapa Milho e Sorgo. Comunicado técnico, 170).

MIRANDA, J. E.; FERREIRA, A. C. B. Contra-ataque. Caderno Técnico Cultivar, v. 72, p. 7-10, 2005.

MORAeS, A. R. A. de.; LOURENÇÃO, A. L.; PATERNIANI, M. E. A. G. Z. Resistência de híbridos de milho convencionais e isogênicos transgênicos a Spodoptera frugiperda (Lepidoptera: Noctuidae). Bragantia, v. 74, n. 01, p. 50-57, 2015.

NOVAIS, R. F.; NEVES, J. C. L.; BARROS, N. F. Ensaio em ambiente controlado. In: OLIVEIRA, A. J.et al. (Coord.). Métodos de pesquisa em fertilidade do solo. Brasília, DF: EMBRAPA - SEA, 1991. p. 189-253. (EMBRAPA-SEA. Documentos, 3). 
SANTOS, R. L.; TORRES, J. B. Produção da proteína Cry1Ac em algodão transgênico e controle de lagartas. Revista Brasileira de Ciências Agrárias, v. 5, n. 4, p. 509-517, 2010.

SANTOS, W. J. Manejo de pragas do algodão com destaque para o cerrado brasileiro. In: FREIRE, E. (Ed.). Algodão no Cerrado do Brasil. Brasília: Abrapa, 2011. p. 495-566.

SOBERÓN, M.; GILL, S. S.; BRAVO, A. Signaling versus punching hole: how do Bacillus thuringiensis toxins kill insect midgut cells? Cellular and Molecular Life Sciences, v. 66, p. 1337-1349, 2009.

TORRES, J. B.; RUBERSON, J. R.; WHITEHOUSE, M. Transgenic cotton for sustainable pest management: a review. In: LICHTFOUSE, E.(Org.). Organic farming, pest control and remediation of soil pollutants: sustainable agriculture reviews. Dordrecht: Springer, 2009. p. 15-54.

WAQUIL, J. M.; VILELLA, F. M. F.; FOSTER, J. E. Resistência de milho (Zea mays L.) transgênico à lagarta-do-cartucho, Spodoptera frugiperda (Smith) (Lepidoptera: Noctuidae). Revista Brasileira de Milho e Sorgo, v. 1, n. 2, p. 1-11, 2002.

\section{Histórico editorial}

Submetido em: 02/07/2015

Aceito em: 30/09/2015 